UNCLASSIFIED

$A D$

AD-E403 611

Technical Report ARMET-TR-14038

\title{
PROCEDURE DEVELOPMENT TO DETERMINE THE HEAT OF COMBUSTION OF AN ENERGETIC LIQUID BY BOMB CALORIMETRY
}

Peggy Sanchez

Kimberly Griswold

January 2015

U.S. ARMY ARMAMENT RESEARCH, DEVELOPMENT AND
ENGINEERING CENTER

Approved for public release; distribution is unlimited. 


\section{UNCLASSIFIED}

The views, opinions, and/or findings contained in this report are those of the author(s) and should not be construed as an official Department of the Army position, policy, or decision, unless so designated by other documentation.

The citation in this report of the names of commercial firms or commercially available products or services does not constitute official endorsement by or approval of the U.S. Government.

Destroy this report when no longer needed by any method that will prevent disclosure of its contents or reconstruction of the document. Do not return to the originator. 


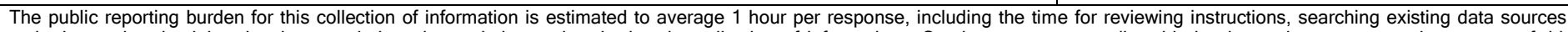

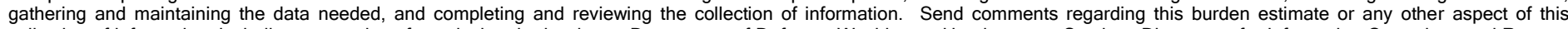

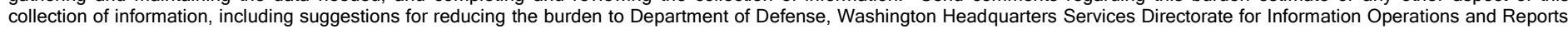

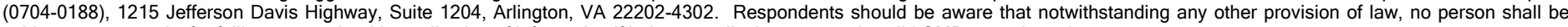
subject to any penalty for failing to comply with a collection of information if it does not display a currently valid OMB control number.

PLEASE DO NOT RETURN YOUR FORM TO THE ABOVE ADDRESS.

\begin{tabular}{|c|c|c|}
$\begin{array}{c}\text { 1. REPORT DATE (DD-MM-YYY) } \\
\text { January 2015 }\end{array}$ & $\begin{array}{l}\text { 2. REPORT TYPE } \\
\text { Final }\end{array}$ & $\begin{array}{c}\text { 3. DATES COVERED (From - To) } \\
\text { January } 2011 \text { to February } 2014\end{array}$ \\
\hline
\end{tabular}

4. TITLE AND SUBTITLE

PROCEDURE DEVELOPMENT TO DETERMINE THE HEAT OF COMBUSTION OF AN ENERGETIC LIQUID BY BOMB CALORIMETRY

6. AUTHORS

Peggy Sanchez and Kimberly Griswold 5a. CONTRACT NUMBER

5b. GRANT NUMBER

5c. PROGRAM ELEMENT NUMBER

5d. PROJECT NUMBER

5e. TASK NUMBER

5f. WORK UNIT NUMBER

7. PERFORMING ORGANIZATION NAME(S) AND ADDRESS(ES)

U.S. Army ARDEC, METC

8. PERFORMING ORGANIZATION REPORT NUMBER

Energetics, Warheads \& Manufacturing Technology Directorate (RDAR-MEE-W)

Picatinny Arsenal, NJ 07806-5000

9. SPONSORING/MONITORING AGENCY NAME(S) AND ADDRESS(ES)

U.S. Army ARDEC, ESIC

Knowledge \& Process Management (RDAR-EIK)

Picatinny Arsenal, NJ 07806-5000

12. DISTRIBUTION/AVAILABILITY STATEMENT

Approved for public release; distribution is unlimited.

13. SUPPLEMENTARY NOTES

14. ABSTRACT

A procedure is reported to obtain heat of formation values from milligram liquid samples in a combustion calorimeter.

\section{SUBJECT TERMS}

Heat of combustion Liquid

16. SECURITY CLASSIFICATION OF:

a. REPORT

b. ABSTRACT

U

$U$

c. THIS PAGE

U
17. LIMITATION OF ABSTRACT

SAR
10. SPONSOR/MONITOR'S ACRONYM(S)

11. SPONSOR/MONITOR'S REPORT NUMBER(S)

Technical Report ARMET-TR-14038 



\section{UNCLASSIFIED}

\section{CONTENTS}

Summary

Introduction

Experimental Section

Materials

1

Methods

2

Results and Discussion

Conclusions

References

Distribution List 



\section{UNCLASSIFIED}

\section{SUMMARY}

An accurate value of the heat of formation $\left(\mathrm{H}_{\mathrm{f}}\right)$ is necessary to estimate the explosive performance of energetic materials. Estimates may be calculated; however, the standard deviation of high nitrogen compounds and energetic salts remains quite large. Although the experimental determination of the heat of formation of solids is easily determined in a combustion calorimeter equipped with an oxygen bomb, the accurate combustion of milligram quantities of liquids can be difficult to obtain. This report includes the process used to develop the procedure to experimentally determine the heat of formation of a liquid using only $20 \mathrm{mg}$ of sample.

\section{INTRODUCTION}

The standard enthalpy of formation or standard heat of formation is a critical identifying physical characteristic of a chemical compound. Estimates of heat of formation can be calculated computationally or the value can be observed experimentally by determining the heat of combustion $\left(\mathrm{H}_{\mathrm{c}}\right)$ in a bomb calorimeter and mathematically converting to the heat of formation.

Determining the heat of combustion and heat of formation of a solid sample is fairly easy to do in a combustion calorimeter with a combustion bomb. The sample is hand pressed in a dye, and the pellet is ignited in oxygen by lighting a fuse wire that is in direct contact with the sample. Very small amounts of energetic material may be used by pressing a pellet composed mostly of a spiking material, or a material with a known heat of formation, such as benzoic acid and subtracting the heat release associated with the benzoic acid. Using small amounts of sample is beneficial from a safety aspect but also in determining the value without sacrificing a large amount of material that may be difficult to synthesize.

While determining the heat of combustion and calculating the heat of formation of a solid is straightforward, experimentally determining the heat of formation of a liquid by bomb calorimetry can be challenging. Running the liquid pooled in the sample well leads to large variations in data due to sample dispersion upon fuse ignition. Variation in data due to sample splashing can be minimized by the use of a combustion capsule; however, these require large amounts of liquids $(\sim 1 \mathrm{~mL})$. Volatile samples are typically sealed in two piece gelatin capsules that are combusted and associated heats subtracted from the total as a spike value. There was a need to design a technique involving absorbing or encapsulating a liquid that would work with minimal amounts of sample in a typical combustion bomb to eliminate error due to sample splashing and incomplete combustion. Energetic synthesis of new compounds can be more effectively characterized by providing a standardized process using a typical combustion bomb with small quantities of liquid samples.

\section{EXPERIMENTAL SECTION}

\section{Materials}

Whatman filter papers 6, 40, 41, 42, and 50 were obtained from Sigma Aldrich. Light mineral oil, toluene, and diethylene glycol were obtained from Fisher Scientific. Butyl carbitol solvent was purchased from Fisher Scientific. Solid benzoic acid pellets were purchased from Parr Instruments.

The heats were determined by using a 6772 calorimetric thermometer attached to a 6725 semi-micro oxygen bomb calorimeter equipped with an 1109/1109A semi-micro oxygen bomb all available from Parr Instruments. 


\section{UNCLASSIFIED}

\section{Methods}

\section{Pellet Preparation}

Paper pellets were prepared by homogenizing pieces of selected filter paper in a hand mill to a fine consistency and hand pressing a pellet in the Parr 2811 Pellet Press weighing between 0.04 to $0.1 \mathrm{~g}$.

\section{Pellet Absorption}

Paper pellets were prepared as per the previously stated procedure. The pellet was weighed and placed onto the sample well of the 1109/1109A semi-micro oxygen bomb, and liquid was added to the pellet drop by drop until the paper would absorb no more material. Excess liquid was dabbed from the pellet, and the mass of liquid was then determined by weighing the pellet in the sample well. The mass of the liquid was obtained by subtracting the mass of the sample well and paper pellet from the total mass.

\section{Calorimeter Operation}

The physical setup and operation of the Parr 6772 calorimetric thermometer, 6725 semi-micro oxygen bomb calorimeter, and 1109/1109A semi-micro oxygen bomb was as per manufacturer instructions (ref. 1). Benzoic acid was used as a standard. When determining the internal energies of liquids absorbed onto the paper pellets, the internal energy of the paper was input as a spike value.

\section{RESULTS AND DISCUSSION}

The optimal material choice for holding a liquid in the combustion bomb needs to meet several criteria: the material must absorb enough liquid so that the energy released is detected by the calorimetric thermometer, the chemical consistency of the material should produce a precise heat of combustion to be entered as a spike value, and the material must combust completely under an oxygen atmosphere. Absorption materials such as sponges and various membranes were investigated; however, after establishing a design of experiment, cellulose filter paper was chosen because of the availability in a chemical laboratory and documented chemical properties such as chemical composition, ash content, and filtration speed. Filtered papers considered were all standard laboratory cellulose filter papers from Whatman. Those selected were qualitative and quantitative papers with a range of filtration speeds from fast to slow and varying ash percentages. See table 1 for selected cellulose filtration papers. 


\section{UNCLASSIFIED}

Table 1

Whatman filter paper chart depicting the physical characteristics of cellulose filter papers types

\begin{tabular}{|c|c|c|c|c|c|c|}
\hline \multicolumn{7}{|c|}{ WHATMAN FILTER PAPER CHART } \\
\hline Filter Speed & 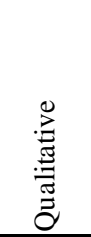 & 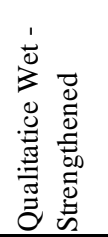 & $\frac{n}{\frac{w}{\pi}}$ & 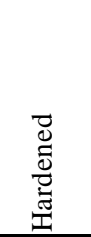 & 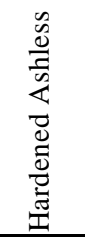 & Retention \\
\hline Fast & 4 & 114,113 & 41 & 54 & 541 & $\begin{array}{l}\text { Coarse and } \\
\text { Gelatinous } \\
\text { Precipitates } \\
\end{array}$ \\
\hline Medium Fast & 1 & 111 & 43 & & & $\begin{array}{l}\text { Medium } \\
\text { Crystalline }\end{array}$ \\
\hline Medium Fast & 2 & & 40 & 52 & 540 & Crystalline \\
\hline Slow & 5,6 & & 44,42 & 50 & 542 & Fine crystalline \\
\hline Ash & $0.06 \%$ & $0.06 \%$ & $0.01 \%$ & $0.03 \%$ & $0.01 \%$ & \\
\hline
\end{tabular}

Note: Selected for this study were papers 6, 40, 41, 42, and 50. Date was compiled from product packaging and Whatman data sheets (ref. 2).

To determine the precision of the internal heats of combustion, the papers were ground to a fine pulp and hand pressed into pellets similar to the procedure for pressing solid samples for the combustion calorimeter. The pellets were evaluated as solid samples run under oxygen and charged at $30 \mathrm{~atm}$. All cellulose papers had internal energies $\left(\Delta U_{c}\right)$ in the range $4000 \mathrm{cal} / \mathrm{g}$, and upon examination, the oxygen bomb was free of residue after combustion. The ashless Whatman 42 and Whatman 41 had standard deviations noticeably lower than the other filter papers with data of $4018.52+/-10.459 \mathrm{cal} / \mathrm{g}(\mathrm{n}=4)$ and $4129.95+/-35.264 \mathrm{cal} / \mathrm{g}(\mathrm{n}=4)$, respectively.

After determining the heat of combustion of the various filter paper types, the maximum amount of liquid that can be absorbed into a pressed pellet was examined. It was necessary to include a material that was capable of carrying enough mass so that the additional heat due to combusting the liquid is measurable by the calorimetric thermometer but still provided the capability of minimizing the total amount of liquid necessary. The amount of liquid that the paper pellet is capable of absorbing was estimated by preparing a pellet in the range of $0.06 \mathrm{~g}$ paper and dropping water onto the pellet until it was completely immersed. The pellet was then removed from the water and excess liquid dabbed from the surface. Each of the cellulose papers was capable of absorbing $0.3 \mathrm{~g}$ or more liquid per gram of paper. The ability of the paper to absorb liquid was not considered an issue as the maximum loading capacity of the oxygen bomb is $0.25 \mathrm{~g}$. When expressed as the amount of liquid absorbed per gram of paper pellet, those papers with medium and slow filtration speeds have a higher loading capacity than those with shorter retention times (fig. 1). Qualitative papers absorb more than quantitative papers and hardened papers. 


\section{UNCLASSIFIED}

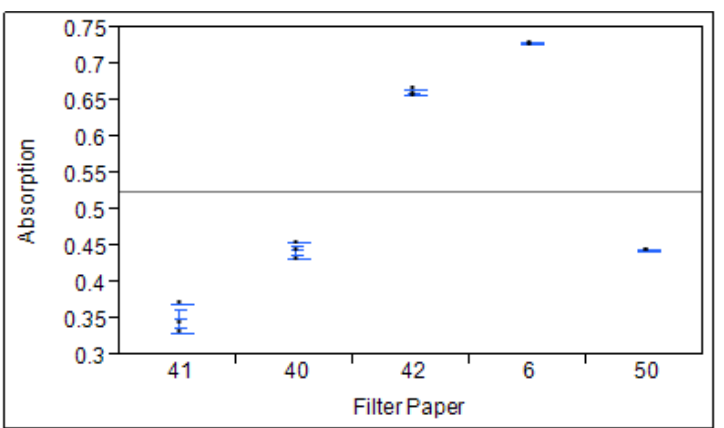

Missing Rows 1

Means and Std Deviations

Std Err

Level Mean Std Dev Mean Lower 95\% Upper 95\%

$\begin{array}{llllll}41 & 0.350133 & 0.020069 & 0.01159 & 0.30028 & 0.39999\end{array}$

$\begin{array}{llllll}40 & 0.443900 & 0.011091 & 0.00640 & 0.41635 & 0.47145\end{array}$

$\begin{array}{llllll}42 & 0.661100 & 0.004709 & 0.00272 & 0.64940 & 0.67280\end{array}$

$\begin{array}{llllll}6 & 0.728067 & 0.001531 & 0.00088 & 0.72426 & 0.73187\end{array}$

$\begin{array}{llllll}50 & 0.444367 & 0.001457 & 0.00084 & 0.44075 & 0.44799\end{array}$

(a) Total absorption

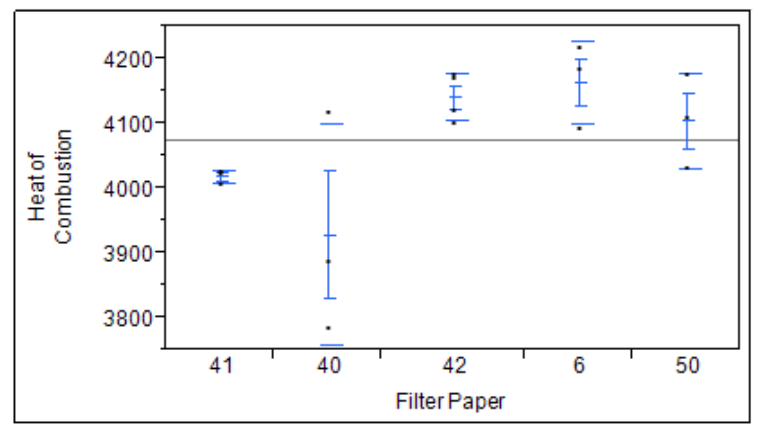

Means and Std Deviations

$\begin{array}{lrrr}\text { Level } & \text { Mean } & \text { Std Dev } & \begin{array}{r}\text { Std Err } \\ \text { Mean }\end{array} \\ 41 & 4018.52 & 10.459 & 6.038 \\ 40 & 3928.39 & 170.827 & 98.627 \\ 42 & 4141.13 & 36.455 & 18.227 \\ 6 & 4164.02 & 64.454 & 37.213 \\ 50 & 4104.74 & 73.300 & 42.320\end{array}$

(c) Heat of combustion

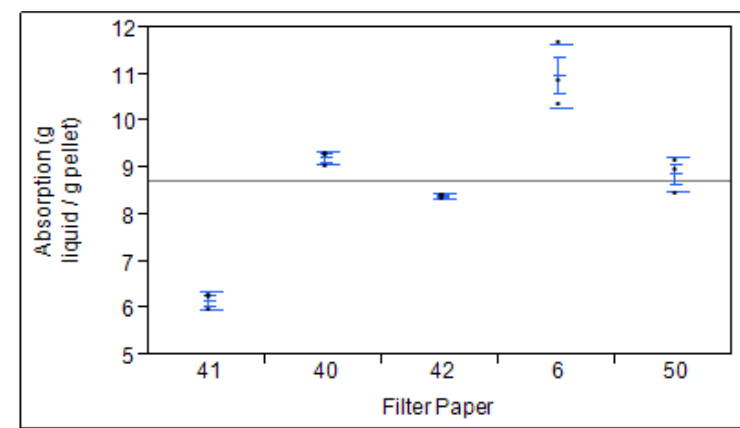

Missing Rows 1

\begin{tabular}{lrrrrrr|}
\multicolumn{6}{l}{ Means and Std Deviations } \\
Level & Mean & Std Dev & $\begin{array}{r}\text { Std Err } \\
\text { Mean }\end{array}$ & Lower 95\% & Upper 95\% \\
41 & 6.1667 & 0.179258 & 0.10349 & 5.7214 & 6.612 \\
40 & 9.2233 & 0.151438 & 0.08743 & 8.8471 & 9.600 \\
42 & 8.4000 & 0.045826 & 0.02646 & 8.2862 & 8.514 \\
6 & 10.9733 & 0.668905 & 0.38619 & 9.3117 & 12.635 \\
50 & 8.8700 & 0.367560 & 0.21221 & 7.9569 & 9.783
\end{tabular}

(b) Grams liquid absorbed per gram pellet

Note: (a) the total mass of water in grams absorbed onto a pressed pellet of cellulose filter paper approximately $0.06 \mathrm{~g}$. (b) normalized absorption expressed as $\mathrm{g}$ liquid/g pellet. (c) the heat associated with combusting the homogenized and pressed cellulose paper in a combustion calorimeter, $\Delta \mathrm{U}_{\mathrm{c}}$, expressed as $\mathrm{cal} / \mathrm{g}$.

Figure 1

Distribution of heat of combustion and absorption values determined for Whatman filter paper types $41,40,42,6$, and 50

Ash content was considered an essential characteristic in down selection of filter types for several reasons; limiting the amount of residue from combusting the paper medium is necessary to determine the completeness of the loaded liquid combustion, and ash content is considered a useful measure of the level of general purity of the cellulose material. The purity of the cellulose paper is essential for determining the precise heat associated with combusting the paper, which is to be subtracted from the experimentally determined liquid-paper values. Therefore, an emphasis was placed on selecting an ashless filter paper with $0.01 \%$ or less ash content. Whatman determines 


\section{UNCLASSIFIED}

the ash content under ideal conditions by ignition of the cellulose filter at $900^{\circ} \mathrm{C}$ in air. In order to mimic incomplete combustion of the filter papers, a sample of paper was ignited at room temperature and let burn until it self-extinguished. The remaining ash content was determined, and results may be seen in table 2. Although bleached printer paper quickly extinguished and left a large portion of ash, the Whatman cellulose filter papers combusted consistently. The consistent properties of the cellulose filter paper provide for a more predictable, complete combustion.

Table 2

Amount of residue remaining after applying a flame to each paper and letting self-extinguish

\begin{tabular}{|c|c|c|c|}
\hline \multicolumn{4}{|c|}{ Paper Burn Residue Test } \\
\hline Filter Paper Type & 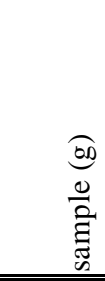 & 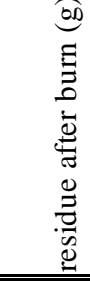 & 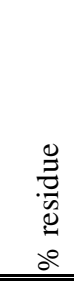 \\
\hline $\begin{array}{l}\text { Whatman Filter paper \#40 } \\
\text { Ashless } \\
0.01 \% \\
\text { Medium }\end{array}$ & 0.149 & 0.02 & 16.00 \\
\hline $\begin{array}{l}\text { Whatman Filter paper \#41 } \\
\text { Ashless } \\
0.01 \% \\
\text { Fast }\end{array}$ & 0.131 & 0.04 & 29.00 \\
\hline $\begin{array}{l}\text { Whatman Filter paper \#42 } \\
\text { Ashless } \\
0.01 \% \\
\text { Slow } \\
\end{array}$ & 0.147 & 0.02 & 15.00 \\
\hline Bleached Printer Paper & 0.11 & 0.08 & 77.00 \\
\hline
\end{tabular}

Down selection of the paper was determined by selecting the material that absorbs the most liquid while exhibiting both a clean combustion and precise heat of combustion. As a precise heat of combustion is the most important parameter considered, Whatman 42 and 41 were chosen. Superior absorption of the faster filter speed papers led to the selection of Whatman 42 . The ash test confirmed that filter paper was superior, specifically quantitative papers with consistent chemical compositions burn more completely in the case of incomplete combustion.

Following the selection of a suitable medium, it was necessary to choose a liquid with a known heat of combustion to use as a calibration point for the instrument when implementing the newly designed process. Initial efforts were focused on using a light white mineral oil. Although the data was acceptable with internal heats of $8894.1052+/-31.22 \mathrm{cal} / \mathrm{g}$, there was no known heat of combustion to compare to because of lack of a molecular formula. Solvents such as toluene and diethylene glycol were considered but not investigated because of their volatile and hygroscopic properties. Butyl carbitol solvent was found to be a suitable candidate for calibration. With as little as $0.02 \mathrm{~g}$ solvent absorbed onto pellets about $0.07 \mathrm{~g}$, the heats of combustion, $-1102.6+/-3.9 \mathrm{kcal} / \mathrm{mol}$, were obtained and compared to the reported literature value of $-1109 \mathrm{kcal} / \mathrm{mol}$ (ref. 3)(table 3 and fig. 2). 


\section{UNCLASSIFIED}

Table 3

Internal energies as reported from the Parr 6772 calorimetric thermometer

\begin{tabular}{|c||c|c|c|c|}
\hline \multicolumn{5}{|c|}{ Filter paper } \\
\hline Liquid sample & $\begin{array}{c}\text { Average Uc } \\
(\mathrm{cal} / \mathrm{g})\end{array}$ & $\begin{array}{c}\text { Standard } \\
\text { deviation }\end{array}$ & $\begin{array}{c}\text { \%Standard } \\
\text { deviation }\end{array}$ & Notes \\
\hline \multicolumn{1}{||}{ Light mineral oil } & -8894.1052 & 31.2249 & 0.0351 & $\begin{array}{c}\text { No molecular } \\
\text { weight, cannot } \\
\text { calculate } \mathrm{H}_{\mathrm{c}}\end{array}$ \\
\hline Toluene & nd & nd & nd & $\begin{array}{c}\text { Too volatile to } \\
\text { obtain mass }\end{array}$ \\
\hline Diethylene glycol & nd & nd & nd & $\begin{array}{c}\text { Too } \\
\text { hygroscopic to } \\
\text { obtain mass }\end{array}$ \\
\hline Butyl carbitol & -6780.5196 & 24.6217 & -0.3631 & $\begin{array}{c}\text { Acceptable } \\
\text { solvent for } \\
\text { procedure }\end{array}$ \\
\hline
\end{tabular}

Note: Data was used to calculate heats of combustion to compare to literature values. nd indicates no data available. The calculated heat of combustion for butyl carbitol from the experimentally determined internal energy of $-6780.5196 \mathrm{cal} / \mathrm{g}$ is $-1102.658 \mathrm{kcal} / \mathrm{mol}$. Butyl carbitol was deemed an acceptable solvent for use as a standard due to minimal hygroscopicity and volatility, precision of internal combustion data, and accuracy of the subsequent calculated heat of combustion within $1 \%$ of the reported literature value. 


\section{UNCLASSIFIED}

\section{Butyl Carbitol}

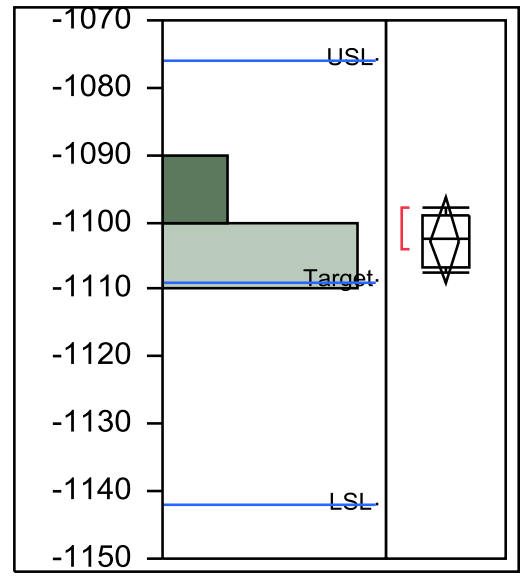

$\begin{array}{lr}\text { Summary Statistics } \\ \text { Mean } & -1102.658 \\ \text { Std Dev } & 3.9943758 \\ \text { Std Err Mean } & 1.9971879 \\ \text { Upper 95\% Mea } & -1096.302 \\ \text { Lower 95\% Mea } & -1109.014\end{array}$

\section{Capability Analysis}

$\begin{array}{lllr}\text { Specification } & \text { Value } & \text { Portion } & \text { \% Actual } \\ \text { Lower Spec Limi } & -1142 & \text { Below LSL } & 0.0000 \\ \text { Spec Target } & -1109 & \text { Above USL } & 0.0000 \\ \text { Upper Spec Limi } & -1076 & \text { Total Outsid } & 0.0000\end{array}$

\section{Long Term Sigma}

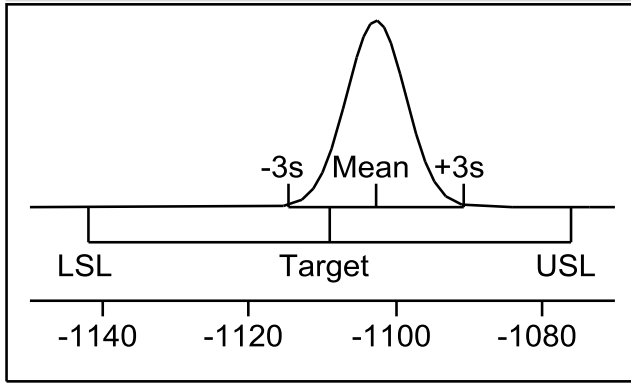

Sigma $=3.9943$

\begin{tabular}{lrrr} 
Capability & Index & Lower CI & Upper CI \\
CP & 2.754 & 0.739 & 4.861 \\
CPK & 2.225 & 0.415 & 4.034 \\
CPM & 1.468 & 0.803 & 2.245 \\
CPL & 3.283 & 0.852 & 5.813 \\
CPU & 2.225 & 0.555 & 3.953 \\
\multicolumn{1}{r}{ Portion } & Percent & PPM & Quality \\
Below LSL & 0.0000 & 0.0000 & \\
Above USL & 0.0000 & 0.0000 & 8.174 \\
Total Outsid & 0.0000 & 0.0000 & 8.174
\end{tabular}

Note: Heat of combustion of butyl carbitol was calculated from the experimentally determined internal energy. The upper and lower specification limits were determined by calculating $3 \%$ from the manufacturer's heat of combustion data. All data is expressed in $\mathrm{kcal} / \mathrm{mol}$. Capability analysis was compiled using JMP software.

Figure 2

Capability analysis of butyl carbitol solvent heat of combustion data 


\section{UNCLASSIFIED}

\section{CONCLUSIONS}

The Parr semi-micro oxygen bomb 1109/1109A in conjunction with the semi-micro calorimeter 6725 offers the unique capability of determining the heat of combustion with a small sample size of 25 to $200 \mathrm{mg}$. This is especially useful when determining the heat of formation of a newly synthesized compound and/or an energetic compound in which little material is available or the material is susceptible to unintended explosion/detonation. Absorbing a minimum of $0.02 \mathrm{~g}$ liquid (butyl carbitol) onto a pressed paper pellet from a quantitative, ashless laboratory filtration paper offers the ability to obtain precise heats of combustion while employing samples smaller than what can be used in conventional liquid methodologies. 


\section{UNCLASSIFIED}

\section{REFERENCES}

1. Parr Instrument Company, 6725 Semimicro Calorimeter Manuals, http://www.parrinst.com/products/oxygen-bomb-calorimeters/6725-semimicrocalorimeter/documents/, 10 September 2014.

2. General Electric Company, GE Healthcare, http://www.gelifesciences.com/webapp/wcs/stores/servlet/catalog/en/GELifeSciencesus/applications/typical-properties-of-filter-papers-and-glass-fiber-filters, 10 September 2014.

3. The Dow Chemical Company, Glycol Ethers, Heat of Combustion of DOW Glycol Ethers, http://msdssearch.dow.com/PublishedLiteratureDOWCOM/dh_0032/0901b80380032296.pdf?file path=oxysolvents/pdfs/noreg/110-00666.pdf\&fromPage=GetDoc, 23 July 2012. 



\section{UNCLASSIFIED}

\section{DISTRIBUTION LIST}

U.S. Army ARDEC

ATTN: RDAR-EIK

RDAR-GC

RDAR-MEE-W, P. Sanchez

RDAR-MEE-M, K. Griswold

Picatinny Arsenal, NJ 07806-5000

Defense Technical Information Center (DTIC)

ATTN: Accessions Division

8725 John J. Kingman Road, Ste 0944

Fort Belvoir, VA 22060-6218

GIDEP Operations Center

P.O. Box 8000

Corona, CA 91718-8000

gidep@gidep.org 


\section{UNCLASSIFIED}

REVIEW AND APPROVAL OF ARDEC TECHNICAL REPORTS

Procedure Develepment to Determine the Heat of Combustion of an Energetic Liquid by Bomb Calorimetry

Trte
$\begin{aligned} & \text { Peggy Sanchez } \\ & \text { Author/Project Engineer }\end{aligned}$ $\begin{aligned} & \text { Date received by LRED } \\ & \begin{array}{l}\text { X2770 } \\ \text { Extension }\end{array}\end{aligned}$

\section{PART 1. Must be signed before the report can be edited.}

a. The draft copy of this report has been reviewed for technical accuracy and is approved for editing.

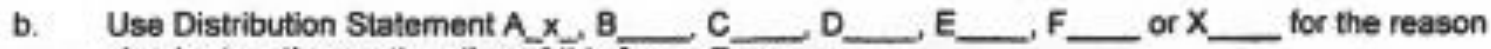
checked on the continuation of this form. Reason:

1. If Statement A is selected, the report will be released to the National Technical Information Service (NTIS) for sale to the general public. Only unclassified reports whose distribution is not limited or controlled in any way are released to NTIS.

2. If Statement B, C, D, E, F, or X is selected, the report will be released to the Defense Technical Information Center (DTIC) which will limit distribution according to the conditions indicated in the statement.

c. The distribution list for this report has been reviewed for accuracy and completeness.

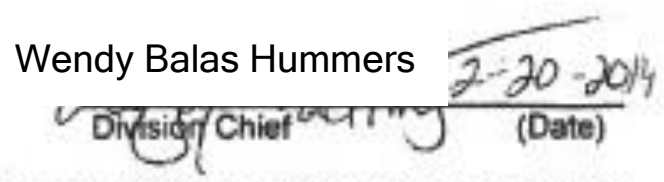

d. This draft copy of this report has been reviewed for sensitive material and approved by the

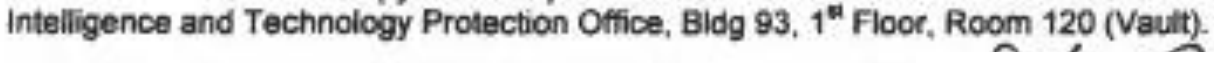

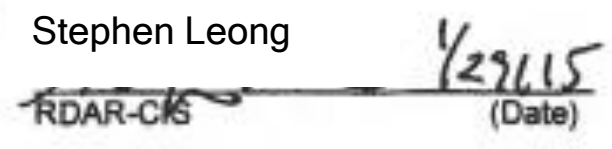

PART 2. To be signed either when draft report is submitted or after review of reproduction copy.

This report is approved for publication.

\begin{tabular}{|c|c|}
\hline Wendy Balas Hummers & $2-20-2014$ \\
\hline Dovisionetief "acting & (Date) \\
\hline
\end{tabular}

LRED 49 supersedes SMCAR Form 49, 20 Dec 06 